\title{
Book Review: Spin Current
}

\author{
Atsufumi Hirohata* \\ Department of Electronic Engineering, University of York, York, United Kingdom
}

Keywords: spintronics, efficiency, spin current, spin current generation, device application

\section{A Book Review on}

\section{Spin Current}

S. Maekawa, S. O. Valenzuela, E. Saitoh, T. Kimura (Oxford, UK: Oxford University Press), 2017, ISBN: 97801910907380191090735

The second edition of Spin Current has been published in September 2017 by the Oxford University Press [1]. The book covers the fundamental description of a spin-polarized electron (hole) current in various systems. The book is divided into three parts: spin current, spin Hall effect, and spin transfer torque. The principles to generate spin currents are listed in the first part, which overlaps with the scope of this review cluster on "Spin-current generation." In the second part of the book focuses on one of the major spin generation method, the spin Hall effect and associated phenomena based on devices with a current flowing in the plane. The final part of the book provides recent experimental and theoretical progress in devices using the spin transfer torque, which is the other major method for spin generation. However, the principles are categorized based on their physical origins in this book, while they are categorized by their physical phenomena in this cluster. Since some of the principles for the spin-current generation are not covered in this cluster, this book offers an ideal complementarity to this cluster.

In the book, the authors partially discussed the spin-current generation efficiency clearly, which is the most critical figure of merit for device applications. The generation efficiency $(\eta)$ can typically be defined as the generated spin current per unit energy introduced, e.g., the electron-spin-current density generated $\left(j_{\mathrm{s}}\right)$ divided by the electron-charge-current density introduced $\left(j_{\mathrm{c}}\right): \eta=j_{\mathrm{s}} / j_{\mathrm{c}}[2]$. Here, $j_{\mathrm{s}}$ is commonly deduced from a measured voltage and its magnitude is dependent upon the theoretical model exploited to interpret it. In some devices with a current flowing in the plane, e.g., devices used for spin-orbit torque, spin-torque ferromagnetic resonance and spin-Hall measurements, it is very difficult to measure $j_{\mathrm{s}}$ and it is widely known that $j_{\mathrm{s}}$ is assumed using models, such as parallel conduction, leading to overestimation of $\eta$. As can be seen in Table 1, a series of spin-current generation methods without using systems including interfaces have much higher efficiency than those with interfaces, which is favorable for device applications. For example, an interface between a ferromagnet and a non-magnet for spin injection and electromagnetic wave is limited by their efficiency to be $\sim 20 \%[4,9]$. Note that in Tashiro et al. [9], the efficiency is calculated as a ratio between the absorbed and introduced microwave power, which can provide an indicative efficiency. This is predominantly due to the interfacial spin scattering by the presence of defects and contaminations. By utilizing a highly spin-polarized ferromagnet, such as a halfmetallic Heusler alloy, the efficiency can be increased up to almost $30 \%$ to date [3]. It is therefore very difficult to increase the efficiency significantly unless a new half-metallic ferromagnetic material or a new device-fabrication process is developed for the realization of a very sharp interface against a non-magnet.

On the other hand, $100 \%$ generation efficiency of spin currents is predicted to occur in non-magnetic materials under certain conditions [12]. For example, a topological 
TABLE 1 | List of spin-current generation efficiency using various methods.

\begin{tabular}{|c|c|c|c|}
\hline Method & System & Efficiency $(\eta)$ & References \\
\hline \multirow[t]{4}{*}{ Spin injection } & $\begin{array}{l}\text { Lateral spin-valve: } \\
\mathrm{Co}_{2} \mathrm{FeSi} / \mathrm{Cu} / \mathrm{Co}_{2} \mathrm{FeSi}\end{array}$ & $27 \%$ & [3] \\
\hline & $\begin{array}{l}\text { Spin Hall: } \mathrm{Pt}_{0.85} \mathrm{Hf}_{0.15} \\
\text { (5.5)/Pt (0.5)/Co (1) (nm) }\end{array}$ & $(23 \pm 2) \%$ & [4] \\
\hline & $\begin{array}{l}\text { Topological insulator: } \\
\left(\mathrm{Bi}_{1-x} \mathrm{Sb}_{x}\right)_{2} \mathrm{Te}_{3} \text { thin films }\end{array}$ & $45 \sim 57 \%$ (max) & {$[5]$} \\
\hline & $\begin{array}{l}\text { Quantum spin Hall: } \\
\mathrm{HgTe} /(\mathrm{Hg}, \mathrm{Cd}) \mathrm{Te}\end{array}$ & $100 \%$ & {$[6]$} \\
\hline Magnetic field & $\begin{array}{l}\text { (Stray field from a } \\
\text { ferromagnet) }\end{array}$ & $\mathrm{N} / \mathrm{A}$ & {$[7]$} \\
\hline $\begin{array}{l}\text { Electric field } \\
\text { application }\end{array}$ & $\begin{array}{l}\text { (Interfacial band changes } \\
\text { under a field) }\end{array}$ & $\mathrm{N} / \mathrm{A}$ & [8] \\
\hline $\begin{array}{l}\text { Electromagnetic } \\
\text { wave }\end{array}$ & Spin pumping: $\mathrm{Y}_{3} \mathrm{Fe}_{5} \mathrm{O}_{12} / \mathrm{Pt}$ & $\sim 20 \%$ & [9] \\
\hline $\begin{array}{l}\text { Zeeman } \\
\text { splitting }\end{array}$ & $\begin{array}{l}\text { (Intrinsic Zeeman splitting at } \\
\text { low temperature) }\end{array}$ & $\mathrm{N} / \mathrm{A}$ & {$[10]$} \\
\hline $\begin{array}{l}\text { Thermal } \\
\text { gradient }\end{array}$ & $\mathrm{Pt} / \mathrm{Ni}_{0.2} \mathrm{Zn}_{0.3} \mathrm{Fe}_{2.5} \mathrm{O}_{4}$ film & $10^{-3} \%$ & [11] \\
\hline Berry phase & $\begin{array}{l}\text { (Geometrical phase } \\
\text { introduced by a field) }\end{array}$ & 100\% (theory) & [12] \\
\hline $\begin{array}{l}\text { Mechanical } \\
\text { rotation }\end{array}$ & $\begin{array}{l}\text { (Electrical motor for } \\
\text { mechanical rotation) }\end{array}$ & $\mathrm{N} / \mathrm{A}$ & {$[1]$} \\
\hline
\end{tabular}

\section{REFERENCES}

1. Maekawa S, Valenzuela S, Saitoh E, Kimura T. (eds.). Spin Current. Oxford: Oxford University Press (2017).

2. Lesne E, Fu Y, Oyarzun S, Rojas-Sánchez JC, Vaz DC, Naganuma $\mathrm{H}$, et al. Highly efficient and tunable spin-to-charge conversion through Rashba coupling at oxide interfaces. Nat Mater. (2016) 15:1261-66. doi: 10.1038/nmat4726

3. Kimura T, Hashimoto N, Yamada S, Miyao M, Hamaya K. Room-temperature generation of giant pure spin currents using epitaxial $\mathrm{Co}_{2} \mathrm{FeSi}$ spin injectors. NPG Asia Mater. (2012) 4:e9. doi: 10.1038/am.2012.16

4. Nguyen M-H, Zhao M, Ralph DC, Buhrman RA. Enhanced spin hall torque efficiency in Pt100-xAlx and Pt100-xHfx alloys arising from the intrinsic spin Hall effect. Appl Phys Lett. (2016) 108:242407. doi: 10.1063/1.4953768

5. Kondou K, Yoshimi R, Tsukazaki A, Fukuma Y, Matsuno J, Takahashi KS, et al. Fermi-level-dependent charge-to-spin current conversion by Dirac surface states of topological insulators. Nat Phys. (2016) 12:1027.

6. König M, Wiedmann S, Brüne C, Roth A, Buhmann H, Molenkamp LW, et al. Quantum spin hall insulator state in HgTe quantum wells. Science (2007) 318:766. doi: 10.1126/science.1148047

7. Hirohata A. Spin Transport and Magnetic Domain Configurations in Magnetic Thin Films and Mesoscopic Structures. Ph.D. thesis, University of Cambridge (2000).

8. Ohno H, Chiba D, Matsukura F, Omiya T, Abe E, Dietl T, et al. Electric-field control of ferromagnetism. Nature (2000) 408:944-46. doi: 10.1038/35050040 insulator is experimentally demonstrated to generate a spin current with $\eta$ to be up to $\sim 60 \%$ [5]. This is the maximum value reported to date but it is under debate [13]. A mechanicallyinduced spin current to be generated in a non-magnet with a large spin-orbit coupling is also expected to have a high efficiency of up to $100 \%$ in theory [1], which is governed by the efficiency of the electrical motor to rotate the object ${ }^{1}$. It is therefore important to discuss the spin-current generation efficiency of each method in details. Some of the systems may be difficult to be realized experimentally but they may hold the key for the future design of spintronic applications. It would therefore be useful to include a chapter to discuss the spin-current generation efficiency in their next revision.

\section{AUTHOR CONTRIBUTIONS}

The author confirms being the sole contributor of this work and approved it for publication.

\section{ACKNOWLEDGMENTS}

The author would like to thank the financial support by the EPSRC (EP/M02458X/1). ${ }_{1}^{1}$ Available online at: https://www.energy.gov/sites/prod/files/2014/04/f15/
10097517.pdf

9. Tashiro T, Matsuura S, Nomura A, Watanabe S, Kang K, Sirringhaus H, et al. Spin-current emission governed by nonlinear spin dynamics. Sci Rep. (2015) 5:15158. doi: 10.1038/srep15158

10. Munekata H, Ohno H, von Molnar S, Segmüller A, Chang LL, Esaki L. Diluted magnetic III-V semiconductors. Phys Rev Lett. (1989) 63:1849.

11. Kirihara A, Kondo K, Ishida M, Ihara K, Iwasaki Y, Someya H, et al. Flexible heat-flow sensing sheets based on the longitudinal spin Seebeck effect using one-dimensional spin-current conducting films. Sci Rep. (2016) 6:23114. doi: 10.1038/srep23114

12. Loss D, Goldbart PM. Persistent currents from Berry's phase in mesoscopic systems. Phys Rev B (1992) 45:13544.

13. Yasuda K, Tsukazaki A, Yoshimi R, Kondou K, Takahashi KS, Otani Y, et al. Current-nonlinear hall effect and spin-orbit torque magnetization switching in a magnetic topological insulator. Phys Rev Lett. (2017) 119:137204.

Conflict of Interest Statement: The author declares that the research was conducted in the absence of any commercial or financial relationships that could be construed as a potential conflict of interest.

Copyright $\odot 2018$ Hirohata. This is an open-access article distributed under the terms of the Creative Commons Attribution License (CC BY). The use, distribution or reproduction in other forums is permitted, provided the original author(s) and the copyright owner are credited and that the original publication in this journal is cited, in accordance with accepted academic practice. No use, distribution or reproduction is permitted which does not comply with these terms. 